\title{
Emme Havası Giriş Sıcaklığı ve Ön Karışımlı Yakıt Oranının RCCI Yanma Karakteristiklerine ve Motor Performansina Etkileri
}

\author{
Ahmet UYUMAZ ${ }^{1 *}$, Hamit SOLMAZ ${ }^{2}$ \\ ${ }^{1}$ Mehmet Akif Ersoy Üniversitesi, Teknik Bilimler Meslek Yüksekokulu,Otomotiv Teknolojisi Programı, BURDUR \\ ${ }^{2}$ Gazi Üniversitesi, Teknoloji Fakültesi, Otomotiv Mühendisliği Bölümü, ANKARA \\ (Geliş/Received : 17.08.2016; Kabul/Accepted : 02.11.2016)
}

ÖZ

$\mathrm{Bu}$ çalışmada emme havası giriş sıcaklığı ve ön karışım yakıt oranının reaktif kontrollü sıkıştırma ile ateşlemeli (RCCI) yanma karakteristikleri ve motor performansı üzerindeki etkileri deneysel olarak araştırılmıştır. Bu amaçla dört silindirli, dört zamanl, direkt enjeksiyonlu benzinli motor RCCI modda $1000 \mathrm{~d} / \mathrm{d}$ 'da $40^{\circ} \mathrm{C}, 60^{\circ} \mathrm{C}$ ve $80^{\circ} \mathrm{C}$ emme havası giriş sıcaklıklarında PRF20, PRF40 ve PRF 60 yakıtları ile stokiyometrik karışım oranında ve tam yükte çalıştırılmışıtır. Emme havası giriş sıcaklığı ve ön karışım oranı arttıkça maksimum silindir basıncının ve 1Sı dağılımının arttığı, yanmanın avansa alındığı görülmüştür. Bunun tersine sabit emme havası giriş sıcaklığında ön karışım oranı arttıkça yanmanın rötara alındığı görülmüştür. Maksimum indike termik verim $60{ }^{\circ} \mathrm{C}$ emme giriş havası sıcaklığında PRF20 yakıtına göre PRF60 yakıtı ile \%7.4 artarak \%32.3 elde edilmiştir. Motor performans1 açısından en uygun yakıtın PRF60 olduğu belirlenmiştir. Deney sonuçları RCCI yanmasının emme havası giriş sıcaklığ 1 ve ön karışım yakıt oranından hassas bir şekilde etkilendiğini, yanma fazının emme giriş sıcaklığı ve ön karışım yakıt oranı ile kontrol edilebileceğini göstermiştir.

Anahtar Kelimeler: Reaktif kontrollü sıkıştırma ile ateşlemeli yanma (RCCI), emme havası giriş sıcaklığı, ön karışım yakıt oranı, yanma, motor performansı.

\section{The Effects of Inlet Air Temperature and Premixed Fuel Ratio on RCCI Combustion and Engine Performance Characteristics}

\begin{abstract}
In this study, the effects of inlet air temperature and premixed fuel ratio on RCCI combustion and engine performance characteristics were investigated experimentally. For this purpose, a four cylinder, four stroke, direct injection gasoline engine was operated on RCCI mode with PRF20, PRF40 and PRF60 at $1000 \mathrm{rpm}$, stoichiometric ratio, inlet air temperature of $40^{\circ} \mathrm{C}, 60^{\circ} \mathrm{C}$, $80^{\circ} \mathrm{C}$ and full load condition. It was seen that maximum in-cylinder pressure and heat release rate increased and advanced with the increase of inlet air temperature and premixed fuel ratio. On the contrary, it was found that combustion was delayed with the increase of premixed fuel ratio at a given inlet air temperature. Indicated thermal efficiency increased by about $7.4 \%$ with PRF60 compared to PRF20 and was obtained $32.3 \%$ at $60{ }^{\circ} \mathrm{C}$ inlet air temperature. It was determined that PRF60 was the most suitable fuel in view of engine performance. Test results showed that RCCI combustion was sensitively influenced by inlet air temperature and premixed fuel ratio and combustion phasing can be controlled with inlet air temperature and premixed fuel ratio.
\end{abstract}

Keywords: RCCI, inlet air temperature, premixed fuel ratio, combustion, engine performance.

\section{GİRIŞ (INTRODUCTION)}

Artan fosil kökenli yakıt fiyatları ve zararlı egzoz gazlarının azaltılması noktasında içten yanmalı motorların verimlerinin arttırılmas1 gerekmektedir. Bununla birlikte egzoz emisyon standartlarındaki sınırlamalar düşük emisyonlu ve verimi yüksek motorların geliştirilmesiyle sağlanması mümkün görünmektedir. Gerekli emisyon standartların karşılanması ve daha verimli içten yanmalı motorların

\footnotetext{
*Sorumlu Yazar (Corresponding Author)

e-posta:auyumaz@mehmetakif.edu.tr

Digital Object Identifier (DOI)
}

geliştirilmesinde homojen dolgulu sıkıştırma ile ateşlemeli (HCCI) yanma, ön karışımlı sıkıştırma ile ateşlemeli (PCCI) yanma, kısmi ön karışımlı (PPC) ve reaktif kontrollü sıkıştırma ile ateşlemeli (RCCI) yanma modları uygulanmaktadır [1-6]. Egzoz gazlarının azaltılmasında kullanılan sistemler hem maliyeti arttırmakta hem de yakıt tüketiminin artışına neden olmaktadır. Özellikle dizel motorlarda karışımın homojen olmamasına bağlı olarak lokal zengin ve fakir karışım bölgeleri oluşmakta, yanma odasında zengin ve yüksek sicaklıkta gerçekleşen yanma sonucu $\mathrm{NO}_{\mathrm{x}}$ ve is emisyonları açığa çıkabilmektedir [7-10]. Bu noktada egzoz gazlarının indirgenmesi ve ısıl verimin arttırılması 
amacıyla araştırmacılar düşük sıcaklık yanma modları üzerinde yoğunlaşmaktadırlar. Düşük sicaklıkta meydana gelen yanma $\mathrm{NO}_{\mathrm{x}}$ oluşumunu engellemektedir. Aynı zamanda tutuşma gecikmesi süresi uzayarak daha homojen bir karışımın oluşturulması için zaman tanınmış olmaktadır $[8,11,12]$. HCCI yanması yüksek yüklerde vuruntu, düşük yüklerde ateşlenememe problemlerinden dolay motor çalışma aralı̆̆ı sınırlı kalmaktadır. HCCI yanması üzerinde direkt kontrol mekanizmas olmadığından basınç artış oranı ve hızlı bir ısı dağılımı görülmektedir. Düşük sıcaklıkta meydana gelen RCCI yanması emme havası basincinın arttırılmasına ve EGR uygulanarak karışımın seyreltilmesine imkân verilmektedir. Kimyasal kinetiklerin kontrol ettiği düşük sıcaklık yanma modunda yanmanın bașlangıcı ve bitiși kontrol edilerek verim arttırılabilmektedir [13]. RCCI yanması düşük sıcaklıklarda meydana geldiğinden özellikle düşük motor yüklerinde $\mathrm{CO}$ ve $\mathrm{HC}$ emisyonları artmaktadır. Farklı reaktif özelliklerde yakıtlar kullanılarak ve emme havası giriș sıcaklığ 1 arttırılarak $\mathrm{CO}$ ve $\mathrm{HC}$ emisyonları azaltılabilmekte ve yanma kontrol edilebilmektedir. Kokjohn ve dĭg. [7] hafif ve ağır yük motorunda RCCI yanma modunu incelemişlerdir. Her iki motorda da $\mathrm{NO}_{\mathrm{x}}$ emisyonlarının $0.05 \mathrm{~g} / \mathrm{kW}-\mathrm{h}$, is emisyonlarının $0.01 \mathrm{~g} / \mathrm{kW}$-h ve vuruntu yoğunluğunun 4 $\mathrm{MW} / \mathrm{m}^{2}$ değerinin altına düştüğünü görmüşlerdir. Hanson ve diğ. [14] RCCI yanmasını düşük yüklerde incelemişlerdir. 4,5 brüt imep değerinde $\% 54$ indike termik verimin elde edildiğini görmüşlerdir. Bununla birlikte $\mathrm{NO}_{\mathrm{x}}$ ve duman emisyonlarının US EPA 2010 emisyon sınırlarının altında olduğunu gözlemlemişlerdir. Dempsey ve diğ. [15] dört silindirli RCCI bir motorda partikül madde emisyonlarının değişimini incelemişlerdir. RCCI yanma modunda sıfıra yakın partkül madde açığa çıktığını belirtmişlerdir. Hanson ve Reitz [16] RCCI yanmasını ve konvansiyonel dizel yanmasını dört silindirli bir motorda emisyonlar ve motor performansı açısından karşılaştırmışlardır. RCCI yanması ile konvansiyonel dizel yanmasına göre daha düşük $\mathrm{NO}_{\mathrm{x}}$ ve duman, daha fazla $\mathrm{HC}$ ve $\mathrm{CO}$ emisyonu açığa çıktığını göstermişlerdir. Wissink ve diğ. [17] Fourier analizi ile basınç dalgalanmaları ve 1s1 dağılımlarını HCCI, RCCI ve konvansiyonel dizel yanma modlarında incelemişler, verim ve $\mathrm{NO}_{\mathrm{x}}$ emisyonlarının değişimini karşılaştırmışlardır. HCCI ve RCCI yanmasında tüm frekans modlarında azalma tespit etmişlerdir. Dizel yanması ile daha fazla güç çıkışının elde edildiğini görmüşlerdir. Pohlkamp ve Reitz [18] dizel ve benzin yakıtlarını kullanarak RCCI modda $\% 25$, $\% 50$ ve \% 75 yükte çalıştırılan bir motorda emme havası giriş sıcaklığının ve enjeksiyon zamanlamasının verim, emisyonlar ve yanma kararlılığı üzerindeki etkilerini incelemişlerdir. \% 75 motor yükünde dizel yanmasına göre $\% 3$ daha fazla verim göstermiştir. Bununla birlikte dizel yanmasına göre $\mathrm{NO}_{\mathrm{x}}$ ve is emisyonlarında azalma $\mathrm{HC}$ ve $\mathrm{CO}$ emisyonlarında artış gözlemişlerdir. Benajes ve diğ. [19] yüksek ve düşük reaksiyon değerlerine sahip benzin ve dizel yakıtları ile gerçekleştirilen RCCI yanmasını deneysel ve nümerik olarak incelemişlerdir.
Dizel enjeksiyonu ile yanmanın başladığını ardından benzin-hava karışımının yanmaya iştirak ettiğini belirtmişlerdir. Dizel/benzin oranı azaldıkça tutuşma gecikmesi süresinin arttığını, karışımın elde edilmesi için gereken süresinin uzadığını göstermişlerdir. Benajes ve diğ. [20] bir başka çalışmasında direkt enjeksiyon zamanlamasının ve karışım oranının RCCI motorda performansa ve emisyonlara etkilerini deneysel olarak araştırmışlardır. Deneyler porttan E10-95, E10-98, E2095 ve E85 yakıtları direkt silindir içine dizel yakıt püskürtülerek $1200 \mathrm{~d} / \mathrm{d}$ 'da gerçekleştirilmiştir. E85 yakıtı ile yapılan deneylerde kararlı yanmanın gerçekleşebilmesi için dikkate değer oranda dizel yakıtının olması gerektiğini görmüşlerdir. Bu durumun $\mathrm{NO}_{\mathrm{x}}$ emisyonlarını ve vuruntu yoğunluğunu arttırdığını gözlemlemişlerdir. Zhu ve diğ. [21] n-heptan ve benzin yakıtlarını kullanarak gerçekleştirdikleri RCCI yanmasını ve emisyon değerlerini tek silindirli bir motorda farklı enjeksiyon zamanlaması ve ön karışım oranlarında incelemişlerdir. Enjeksiyon zamanlamasının avansa alınması ile tutuşma gecikmesi süresinin arttığını görmüşlerdir. Üç farklı test yakıtı ile yapılan deneylerde $\mathrm{CO}$ ve is emisyonları azalırken $\mathrm{NO}_{\mathrm{x}}$ emisyonlarının arttığını görmüşlerdir. Li ve diğ. [22] benzin ve biyodizel yakıtlarının RCCI yanması üzerindeki etkilerini nümerik olarak KIVA4-CHEMKIN ile incelemişlerdir. Benzin oranı değiştirildiğinde yanma başlangıcının ve yanma fazının kontrol edilebildiğini görmüşlerdir. Aynı zamanda benzin miktarındaki artış ile $\mathrm{NO}_{\mathrm{x}}$ ve is emisyonlarının daha homojen bir yanma ile azaldığını görmüşlerdir. Benajes ve diğ. [23] yeniden reaksiyona girme karakteristiklerinin düşük olduğu yakıtların (porttan E10-95, E10-98, E20-95 ve E85, direkt silindire dizel) ve karışım oranının RCCI yanması ve emisyonlar üzerindeki etkilerini düşük yükte incelemişlerdir. Uygun karışım oranları kullanıldığında azalan yeniden etkinleştirme karakteristikleri ile indike termik verimin \% 4,5 iyileştiğini gözlemlemişlerdir. Qian ve diğ. [24] porttan etanol ve benzin direkt silindir içine n-heptan yakıtlarını püskürterek sağladıkları RCCI yanmasını ve emisyon karakteristiklerini incelemişlerdir. Etanol/nheptan yakıtları kullanıldığında RCCI yanmasında tutuşma gecikmesinin arttığını görmüşlerdir. Artan ön karışım yakıt oranlarında RCCI yanması ile $\mathrm{NO}_{\mathrm{x}}$ ve is emisyonlarının iyileştiğini görmüşlerdir. Farklı karışım oranlarında benzin/n-heptan yakıtı ile etanol/n-heptan yakıtına oranla daha düşük $\mathrm{HC}$, daha fazla $\mathrm{NO}_{\mathrm{x}}$ ve is emisyonu açığa çıkardığı görülmüştür. 0.57 ön karışım oranında benzin/n-heptan ve etanol/n-heptan yakıtları ile maksimum indike termik verim elde edildiğini görmüşlerdir. İndike ortalama efektif basınç (imep) değeri 6 barın üzerinde iken etanol/n-heptan yakıtı ile hesaplanan indike termik verimin benzin/n-heptan yakıtından daha yüksek olduğunu görmüşlerdir. Qian ve diğ. [25] bir başka çalışmasında direkt silindire n-heptan, porttan etanol, n-butanol and n-amil alkol püskürterek gerçekleştirdikleri RCCI yanması ve emisyonları deneysel olarak araştırmışlardır. Çevrim başına sabit ısıl enerjiler göz önüne alındığında ön karışım oranı arttıkça 
$\mathrm{NO}_{x}$ ve is emisyonlarının azaldığını görmüşlerdir. Bunun yanında n-heptan/n-butanol ve n-heptan/n-amil alkol yakıtları karşılaştırıldığında RCCI etanol yanmasında yanma fazının yüksek ön karışım oranlarında rötara alındığını gözlemlemişlerdir. Kakaee ve diğ. [26] doğalgaz ve dizel yakıt karışımları ile sağlanan RCCI yanmasını ve emisyon karakteristiklerini 9 bar imep değerinde nümerik olarak incelemişlerdir. Wobbe sayısının ve motor devrinin önemli derecede RCCI yanmasını ve emisyonları etkilediğini ifade etmişlerdir. Yüksek Wobbe numarası ile daha fazla maksimum silindir basıncı, sıcaklık ve $\mathrm{NO}_{\mathrm{x}}$ ve daha düşük $\mathrm{HC}$ ve $\mathrm{CO}$ emisyonlarının elde edildiğini görmüşlerdir.

Bu çalışmada dört silindirli, dört zamanlı, 2L hacmindeki benzinli bir motorun RCCI motora dönüşümü gerçekleştirilmiştir. Emme havası giriş sıcaklığı ve ön karışım oranının RCCI yanma karakteristikleri ve motor performansı üzerindeki etkileri deneysel olarak araştırılmıştır. $\mathrm{Bu}$ amaçla deney motoru tam yükte, stokiyometrik karışım oranında, 1000 d/d motor devrinde, 40 'KA (ÜÖN'dan önce) enjeksiyon zamanlamasında, farklı emme havası giriş sıcaklıklarında $\left(40^{\circ} \mathrm{C}, 60^{\circ} \mathrm{C}\right.$ ve $\left.80^{\circ} \mathrm{C}\right)$ ve ön karışım oranlarinda (PRF20, PRF40 ve PRF60) RCCI yanma modunda çalıştırılmıştır. Silindir basıncı, 1sı dağılımı, imep, yanma başlangıcı, yanma süresi, kümülatif 1s1 dağılımı, yanma verimi ve indike termik verim gibi yanma ve performans karakteristikleri incelenmiştir.

\section{MATERYAL VE METOT (MATERIAL AND METHOD)}

Emme havası giriş sıcaklığı ve ön karışım yakıt oranının RCCI yanması ve motor performansına etkilerini incelemek için yapılan deneyler Michigan Technological University'de, Advanced Power System Research Center'da gerçekleştirilmiştir. Deney düzeneğinin şematik görünümü Şekil 1'de görülmektedir.
Deney düzeneğinde dinamometreye bağlı deney motorunda lamda, EGR, oranı, gaz kelebeği, konumu, emme havası giriş sıcaklığı, enjeksiyon zamanlaması ve supap zamanlaması gibi parametreler kontrol edilebilmektedir. Deneylerde dört zamanlı, dört silindirli 2 L hacmindeki GM Ecotec benzinli motor kullanılmış, RCCI yanma modunda çalıştırılmıştır. Deney motorunun teknik özellikleri Çizelge 1'de verilmektedir. Deney motoru 460 BG gücünde kontrol edilebilir AC dinamometreye bağlanmış, motor devri ve yükü değiştirilmiştir. Deneyler tam gaz kelebeği açıklığında ve $1000 \mathrm{~d} / \mathrm{d}$ motor devrinde gerçekleştirilmiştir. Motora alınan emme havasının giriş sıcaklığı emme manifoldu ile gaz kelebeği arasına yerleştirilen emme havası 1sıtıcısı ile kontrol edilebilmektedir.

Çizelge 1. Deney motorunun teknik özellikleri (The technical properties of the test engine)

\begin{tabular}{ll}
\hline Model & GM Ecotec LHU Gen I \\
\hline Silindir çapı x Strok [mm] & 86 x 86 \\
Silindir sayısı & 4 \\
Silindir hacmi [L] & 2.0 \\
Sıkıştırma oranı [mm] & $9.2: 1$ \\
Biyel kolu uzunluğu [mm] & 145.5 \\
Maksimum güç [kW & 270 \\
Yakıt enjeksiyon sistemi & Benzinli direkt \\
Supap sistemi & Üstten çift eksantrik, 4 \\
\hline
\end{tabular}

Emme havası giriş sıcaklığ 1 ve ön karıșım yakıt oranının RCCI yanma karakteristikleri üzerindeki etkilerini incelemek için silindir basınc1 115A04 model PCB piezo basınç sensörü ile ölçülmektedir. Ölçülen silindir basıncı 1104CA model DSP şarj amplifikatörü ile yükseltilmiş ACAP yanma analiz sistemi kullanılarak silindir basıncı verileri işlenmiştir. Krank konumunu belirlemek için deney motorunun krank miline $1{ }^{\circ} \mathrm{KA}$ aralığ hassasiyetinde ölçüm yapabilen enkoder bağlanmıștır. Bununla birlikte 700 model Micro Motion yakıt akış

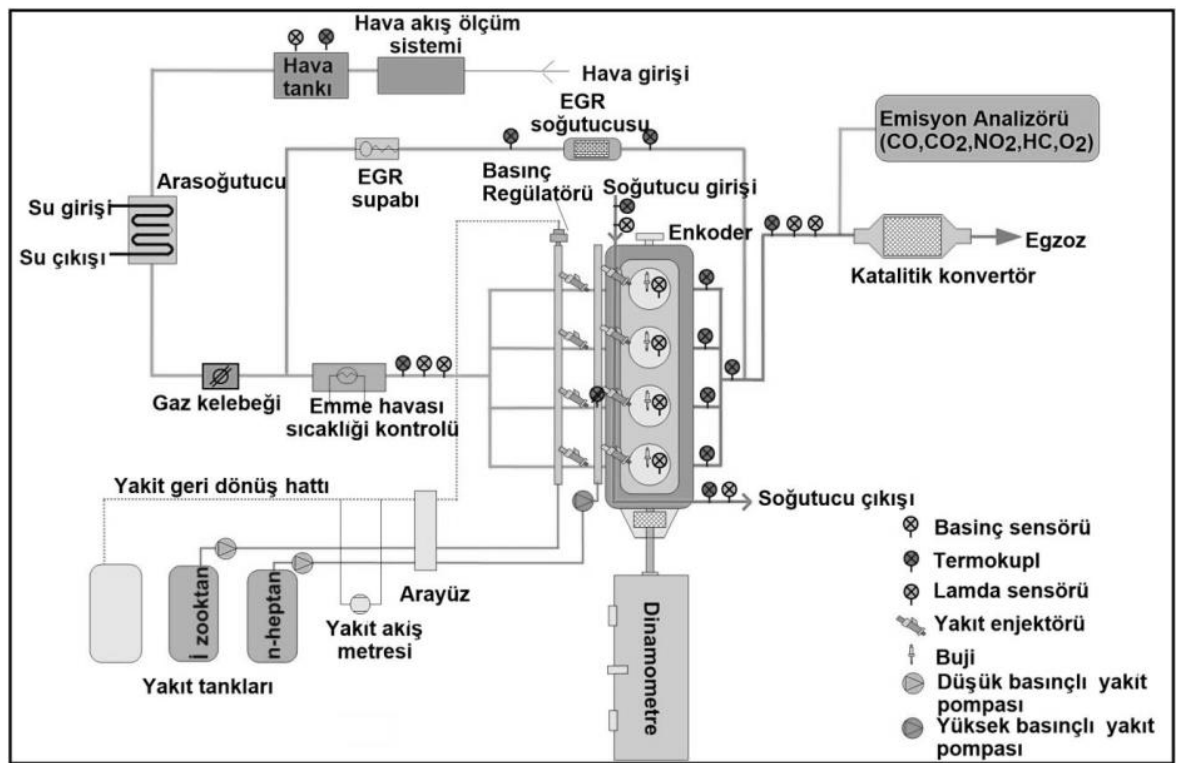

Şekil 1. Deney düzeneğinin şematik görünümü (The schematic view of the experimental setup) 
metresi ile yakıt tüketimi ölçülmüştür. RCCI motor çalışma parametreleri dSPACE MicroAutoBox ve RapidPro üniteleri kullanılarak kumanda edilebilmektedir. Lamda, değişken supap zamanlaması, emme havası giriş sicaklığı, enjeksiyon zamanlaması, gaz kelebeği konumu ve EGR gibi motor çalışma parametrelerin kontrolünü içeren motor yönetim sistemi için MATLAB Simulink modeli geliştirilmiş ve kullanılmıştır. dSPACE ünitesi kullanılarak emme ve egzoz kamların fazı, yakıt hat basıncı, gaz kelebeği konumu, hava-yakıt oranını, krank açısı ve EGR supabı pozisyonu ölçülebilmektedir. Sırasıyla NI TB 4353, NI PXI 6225 and NI PXI 6722 modüllerini içeren National Instrument PXIe 1078 chassis sistemi kullanılarak termokupl, basınç sensörü ve dinamometre kontrol edilebilmektedir. MATLAB kodu hazırlanarak silindir içi basınç verileri kullanılarak yanma analizi gerçekleştirilmiştir. Kullanılan MATLAB programı ile özgül yakıt tüketimi, indike ortalama efektif basınç (imep), indike termik verim, yanma başlangıcı, yanma süresi, yanma verimi, basınç artış oranı, ısı dağılımı ve kümülatif 1sı dağılımı gibi parametreler belirlenebilmekte ve hesaplanabilmektedir. Lab VIEW arayüzü kullanılarak ölçülen veriler görüntülenmiştir. Isı dağılımı analizi için termodinamiğin birinci kanununa dayalı ideal gaz denklemi kullanılmıştır. Isı dağılımı hesaplamasında çevrimde çalışma gazının ideal gaz olduğu kabulü yapılmıştır. Isı dağılımı Eş. (1) ile hesaplanmıştır.

$\frac{d Q}{d \theta}=\frac{k}{k-1} P \frac{d V}{d \theta}+\frac{1}{k-1} V \frac{d P}{d \theta}+\frac{d Q_{\text {heat }}}{d \theta}$

Bu eşitlikte $d Q, d Q_{\text {heat }}, d \theta$ ve $k$ sırasıyla ısı dağılımı, silindir duvarlarına transfer edilen 1sıyı, krank açısı değişimini ve özgül 1sıların oranını göstermektedir. Yanma verimi ise Eş. (2) ile hesaplanmıştır.

$\eta_{\text {yanma }}=\frac{\int_{t y_{\text {bas }}}^{t y_{\text {son }}} \frac{d Q_{g r}}{d \theta} d \theta}{m_{f} Q_{L H V}}$

Burada $t y_{\text {baş }}$ ve $t y_{\text {son }}$ krank açısına bağlı olarak yanma başlangıcını ve sonunu, $\frac{d Q_{g r}}{d \theta}$ krank açısına bağlı olarak toplam 1s1 dağılımını, $Q_{L H V}$ yakıtın alt ısıl değerini, $\boldsymbol{m}_{f}$ bir çevrimde silindire sürülen yakıt miktarını ifade etmektedir [26-30].

Deneylerde ön karışım yakıt oranının ve emme havası giriş sıcaklığının RCCI yanma karakteristikleri ve motor performansı üzerindeki etkileri araştırılmıştır. Benzinli deney motoru izooktan ve n-heptan yakıtları porttan ve direkt silindir içerisine püskürtülerek RCCI yanma modunda çalıştırılmıştır. Deneylerde kullanılan yakıtların özellikleri Çizelge 2'de görülmektedir.
Çizelge 2. İzooktan ve n-heptan yakıtlarının özellikleri (The properties of the iso-octane and n-heptane fuels) [31]

\begin{tabular}{lcc}
\hline & İzooktan & n-heptan \\
\hline Araştırma oktan sayısı & 100 & 0 \\
Kimyasal formülü & $\mathrm{C}_{8} \mathrm{H}_{18}$ & $\mathrm{C}_{7} \mathrm{H}_{16}$ \\
Molekül ağırlığı & 114.23 & 100.21 \\
[gr/mol] & & \\
Yoğunluk [kg/m ${ }^{3}$ & 692 & 695 \\
@ $\left.15.4^{\circ} \mathrm{C}\right]$ & & \\
Kaynama noktası [K] & $372.2-372.6$ & 371 \\
Alt 1sıl değeri $[\mathrm{kJ} / \mathrm{kg}]$ & 44310 & 44566 \\
\hline
\end{tabular}

Deneyler tam yükte, stokiyometrik karışım oranında ( $\lambda=1), \quad 1000 \mathrm{~d} / \mathrm{d}$ motor devrinde, sabit enjeksiyon zamanlamasında $40{ }^{\circ} \mathrm{KA}$ (ÜÖN'dan önce) RCCI yanma modunda gerçekleştirilmiştir. Emme havası giriş sıcaklığı ve ön karışım yakıt oranının RCCI yanması ve performans karakteristikleri üzerindeki etkileri deneysel olarak incelenmiştir. Deneyler Çizelge 3'de belirtilen motor çalışma parametrelerinde gerçekleştirilmiştir.

Çizelge 3. Deney şartları (Test conditions)

\begin{tabular}{lc}
\hline Yakıt & PRF20, PRF40, \\
Motor yükü & Tam yük \\
Motor devri $[\mathrm{d} / \mathrm{d}]$ & 1000 \\
Emme havası giriş sicaklığ1 $\left[{ }^{\circ} \mathrm{C}\right]$ & $40,60,80$ \\
Lamda & 1 \\
Egzoz supabı kapanma & 22 \\
Emme supabı açılma & 22 \\
Enjeksiyon zamanlaması & 40 \\
\hline
\end{tabular}

\section{SONUÇLAR VE TARTIŞMA (RESULTS AND DISCUSSION)}

RCCI yanması emme havası giriş sıcaklığı ve ön karışım oranından oldukça etkilenmektedir. Düşük ve yüksek reaksiyon karakteristiklerine sahip yakıtların kullanılması RCCI yanmasında yaygın olarak kullanılan bir metottur. $\mathrm{Bu}$ çalışmada düşük reaksiyon karakteristiğine sahip izooktan yakıtı porttan, yüksek reaksiyon karakteristiğine sahip n-heptan yakıtı direkt silindire püskürtülerek RCCI yanması sağlanmıștır. Yanma başlangıcı ve yanmanın seyri yakıt özellikleri ve çevrimin başlangıcındaki sıcaklık ve basınç değerleri tarafından kontrol edilebilmektedir. Şekil 2'de Emme havası giriş sıcaklığı ve ön karışım yakıt oranının silindir basıncı ve ısı dağılımı üzerindeki etkileri görülmektedir. Ön karışımlı RCCI yanması yanmanın başlangıcındaki termodinamik şartlara hassas şekilde bağlıdır. Yapılan deneylerde ön karışım oranının değiștirilmesi ile emme havası giriș sıcaklığının geniş bir aralıkta değiştirilmesi mümkün olmuş ve kararlı 
RCCI yanması sağlanmıştır [14]. Şekil 2'de 1Sı dağılımları incelendiğinde RCCI yanmasında düşük sıcaklık ve yüksek sıcaklık reaksiyonlarının meydana geldiği görülmüştür. Düşük ve yüksek sıcaklık reaksiyonları arasında kalan bölge ise negatif sıcaklık katsayılı bölge olarak adlandırılmaktadır. RCCI yanmasında diğer konvansiyonel yanma türlerine göre daha düşük silindir basıncı ve 1sı dağılım gradyanı göstermektedir. Konvansiyonel dizel yanması ile karşılaştırıldığında RCCI yanmasında daha uzun ve yavaş bir ısı dağılımı grafiği elde edilmektedir [18]. Şekil 2'de görüldüğü gibi emme havası giriş sıcaklığı arttıkça tüm ön karışım yakıt oranlarında maksimum silindir basıncının arttığ 1 ve yanmanın avansa alındığ 1 görülmektedir. Emme havası giriş sıcaklığının arttırılması ile yanma odasında reaktifliğin önemli ölçüde arttırıldığ görülmektedir. Bu durum silindir basıncının ve ısı dağ1lımının artışına neden olmaktadır [18]. Özellikle $80{ }^{\circ} \mathrm{C}$ emme havası giriş sıcaklığında önemli derecede yanmanın avansa alındığı, maksimum basıncı arttığı görülmektedir. Düşük sıcaklık reaksiyonlarında $60^{\circ} \mathrm{C}$ ve $40^{\circ} \mathrm{C}$ emme havası giriş sıcaklıklarında önemli bir farklılık görülmemektedir. Benzer şekilde ön karışım yakıt oranı arttırıldıkça maksimum silindir basıncının arttığını ifade etmek mümkündür. RCCI yanması kimyasal kinetikler tarafından kontrol edilen ön karışımlı bir yanmadır. Yüksek emme havası giriş sıcaklığı silindir cidarı sıcaklığının çok fazla azalmasına engel olmakta, yanma iyileşmekte- dir. Çünkü RCCI yanmasında soğuk silindir cidarı kinetik reaksiyon oranının azalmasına neden olarak yanmayı kötüleştirmektedir [16,32]. Aynı zamanda sabit emme havası giriş sıcaklığında ön karışım yakıt oranı arttıkça yanma fazının rötara alındığı görülmektedir [33]. Düşük ön karışım yakıt oranlarında yanmanın n-heptan tarafından kontrol edildiği ifade edilebilir. Buna bağlı olarak ön karışım yakıt oranı arttıkça silindir basıncı ve 1Sı dağılımı artış göstermektedir. Yüksek sıcaklık reaksiyonları boyunca 1sı dağılımının hızlı artışı emme havası giriş sıcaklığının artışı ile gerçekleşmektedir [14, 34].

Ön karışımlı yanma modları içerisinde HCCI yanması üzerinde direkt bir kontrol mekanizması bulunmamaktadır. Dolayısıyla hızlı ve ani bir 1sı dağılımı görülmekte yanma fazının kontrolünde güçlüklerle karşılaşılmaktadır. Bunun sonucunda özellikle yüksek motor yüklerinde aniden gerçekleşen 1sı dağılımı sonucu vuruntu problemi görülmektedir. Fakat RCCI yanmasında farklı yakıt enjeksiyon stratejileri, farklı reaksiyon karakteristiklerine sahip yakıtların kullanılması ve çevrimin başlangıç termodinamik şartlarının değiştirilmesi ile yanma fazı kontrol edilebilmektedir. Bununla birlikte motor performansı da iyileştirilmektedir. Şekil 3'de emme havası giriş sıcaklığı ve ön karışım yakıt oranının imep üzerindeki etkileri görülmektedir. Stokiyometrik oranda yapılan deneylerde emme havası giriş sıcaklığı arttıkça imep değerlerinin arttığı görülmektedir. Maksimum imep değerleri PRF60,
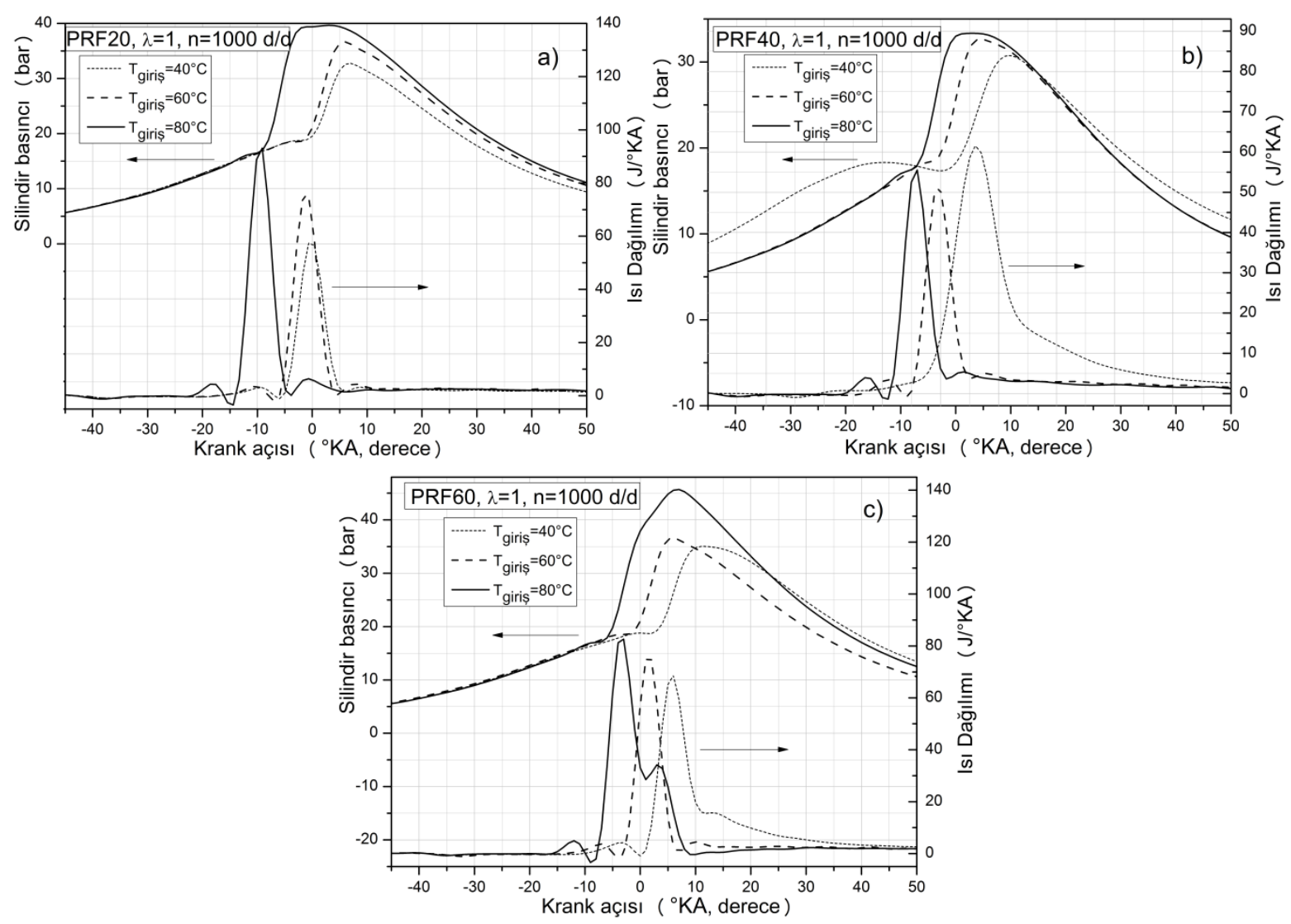

Şekil 2. Emme havası giriş sıcaklığı ve ön karışım yakıt oranının silindir basıncı ve ısı dağılımı üzerindeki etkileri (The effects of inlet air temperature and premixed fuel ratio on cylinder pressure and heat release rate) 
PRF40 ve PRF20 yakıtları ile $80^{\circ} \mathrm{C}$ emme havası giriș s1caklığında sırasıyla 7.09 bar, 6.68 bar ve 4.86 bar olarak kaydedilmiştir. Benzer şekilde ön karışım yakıt oranı arttıkça imep değerlerinin arttığı görülmektedir [35].

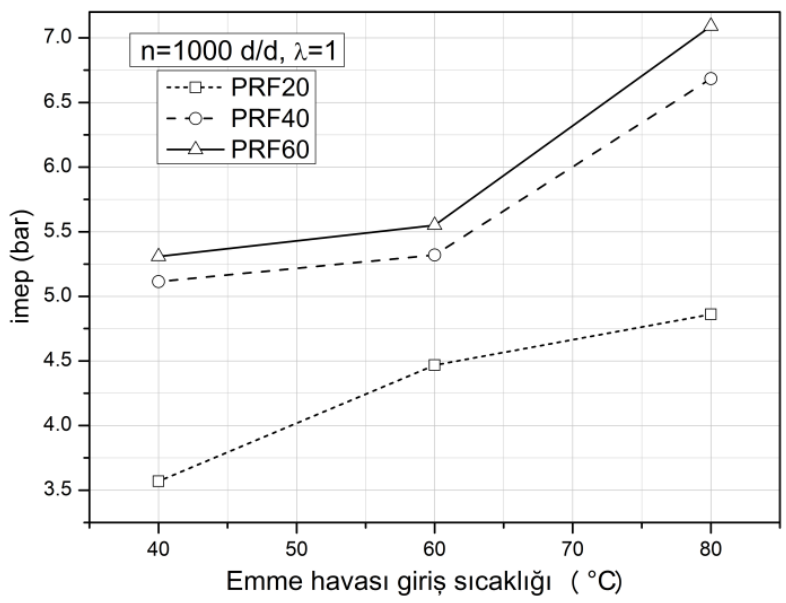

Şekil 3. RCCI yanmasında emme havası giriş sıcaklığı ve ön karıșım yakıt oranının imep üzerindeki etkisi (The effect of inlet air temperature and premixed fuel ratio on imep)
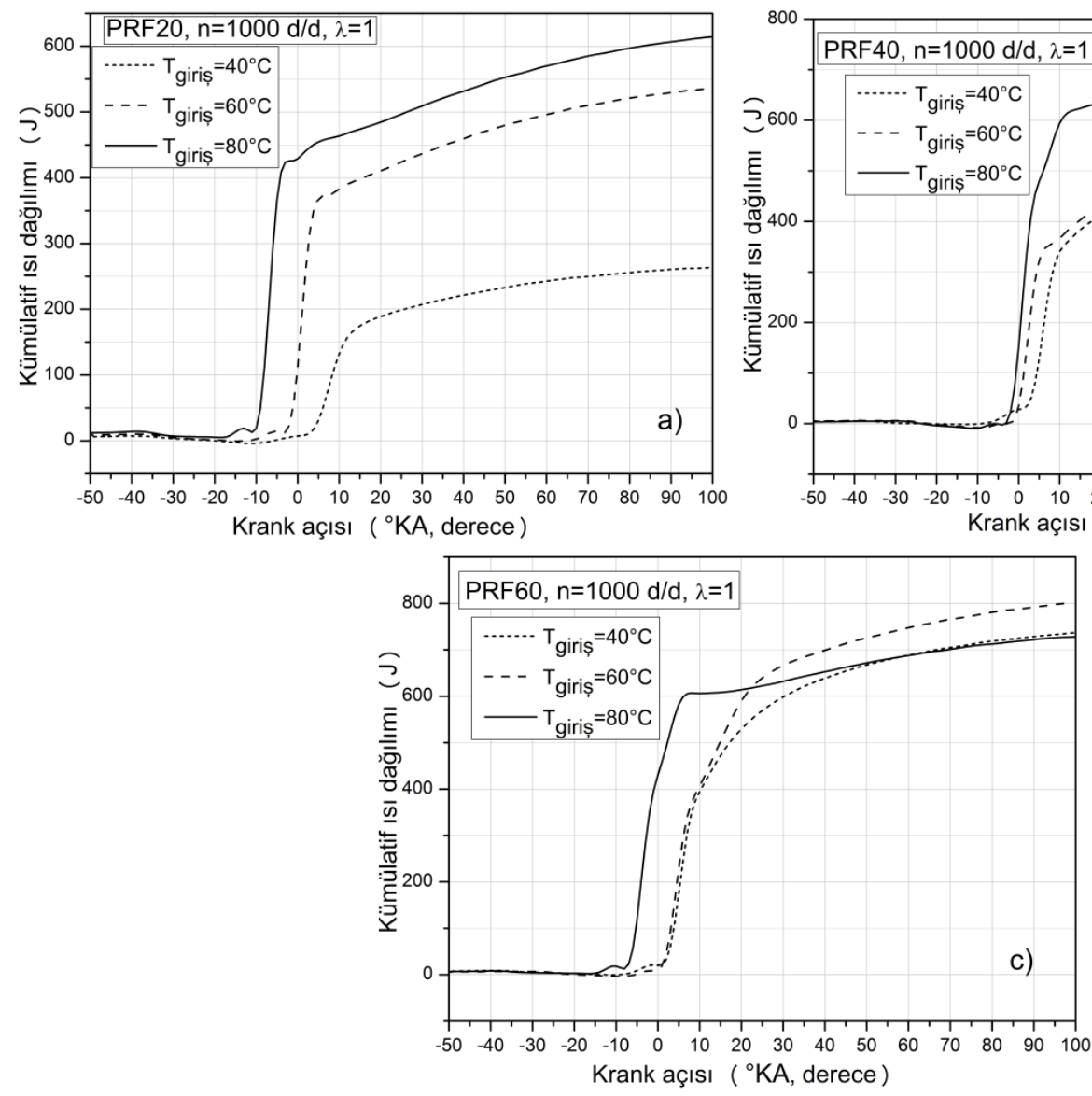

Şekil 4. Kümülatıf ısı dağılımları (Cumulative heat release rates)

Şekil 5 ön karışım yakıt oranının ve emme havası giriş sıcaklığının yanma başlangıcı ve yanma süresi üzerindeki etkilerini göstermektedir. Emme havası giriş sıcaklığının

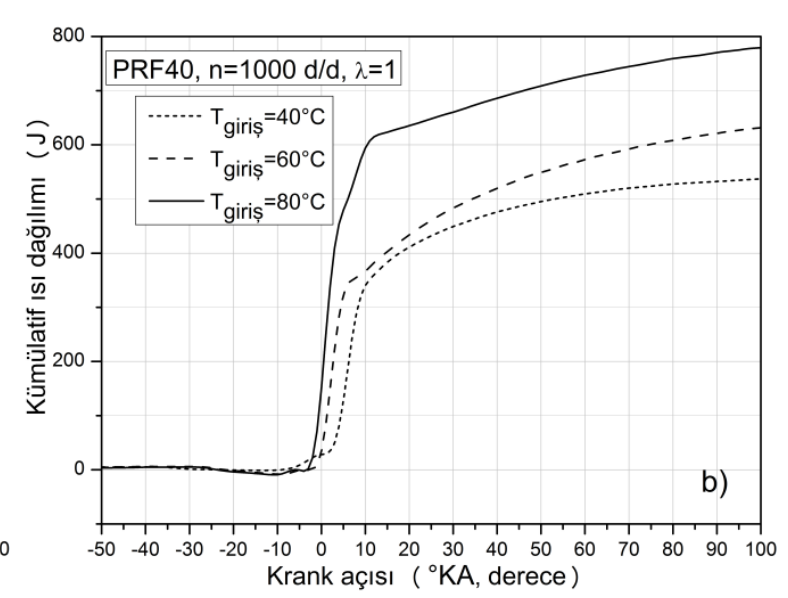

etkilediği en önemli değişkenlerden biri yanmanın başlangıcıdır. Emme havası giriş sıcaklığ 1 arttıkça yanma başlangıcı avansa alınmaktadır. Şekil 5 incelendiğinde RCCI yanma zamanlamasının emme havası giriş sıcaklığı tarafından kontrol edildiği görülmektedir [36]. Emme havası sıcaklığının arttırılması oksidasyon oranını hızlandırarak yanma şartlarını kolaylaştırmaktadır. Bunun tersine sabit emme havası giriş sıcaklığında ön karışım yakıt oranı arttıkça yanmanın rötara alındığını ifade etmek mümkündür. Yüksek emme giriş sıcaklığına bağlı olarak yanma odası sıcaklığı artmakta yanma daha kısa sürmektedir. Şekil 5'de görüldüğü gibi emme giriş sıcaklığı arttıkça yanma süresi kısalmaktadır. Aynı şekilde ön karışım yakıt oranı arttığında yanma süresinin kısaldığ 1 görülmektedir.

Yanma analizinde KA50 silindire alınan karışım kütlesinin yarısının yanmasını tamamladığ denk gelmektedir. KA50 ve termik verim arasında yakın bir ilişki bulunmaktadır. Maksimum termik verim için KA50 ÜÖN'dan hemen sonra (5-10 'KA ÜÖN'dan sonra) elde edilmelidir $[29,30]$. Sekil 6 RCCI yanmasında KA50 ve indike termik verimin değişimini göstermektedir. Emme havası giriş sıcaklığı arttıkça

yanmanın avansa alındığı görülmektedir. Fakat yanmanın çok fazla avansa alınması indike termik verimin azalmasına neden olmaktadır. Ön karışım yakıt 
oranı arttıkça yanmanın rötara alındığı görülmektedir. Maksimum indike termik verim $60^{\circ} \mathrm{C}$ emme giriş sicaklığında PRF20, PRF40 ve PRF60 yakıtları ile sirasiyla \%29.8, \% 31.2 ve \% 32.3 şeklinde elde edilmiştir. Curran ve diğ. [37] tarafindan yapılan çalışmada maksimum verimin KA50 değeri ÜÖN'dan $5^{\circ} \mathrm{KA}$ iken elde edildiğini görmüşlerdir. RCCI yanmasında düşük ve yüksek reaksiyon karakteristiklerine sahip yakıtlar kullanıldığı göz önüne alındığında en uygun yakıtın seçimi önemlidir. Bu noktada indike termik verim ve motor performans1 açısından en uygun yakıtın PRF60 olduğu görülmektedir. oksidasyon oranı artmaktadır. RCCI yanması düşük sicaklıklarda meydana geldiğinden konvansiyonel yanma türlerine göre yanma verimi düşük kalmaktadır. Şekil 7'de emme havası giriş sıcaklığı ve ön karışım oranının yanma verimi üzerindeki etkileri görülmektedir. Termik verime benzer şekilde yanma verimi ön karışım oranı arttıkça artış göstermektedir. Emme havası giriş sıcaklığı arttıkça tüm ön karışım oranlarında yanma verimi artmaktadır. Yanma verimini etkileyen en önemli değişkenlerden biri yanma sonu gaz sıcaklığıdır. Gerçekleştirilen deneylerde emme havası giriş sıcaklığı arttıkça maksimum silindir gaz sıcaklığı artış göstermektedir. Maksimum yanma verimi PRF60 ile 80

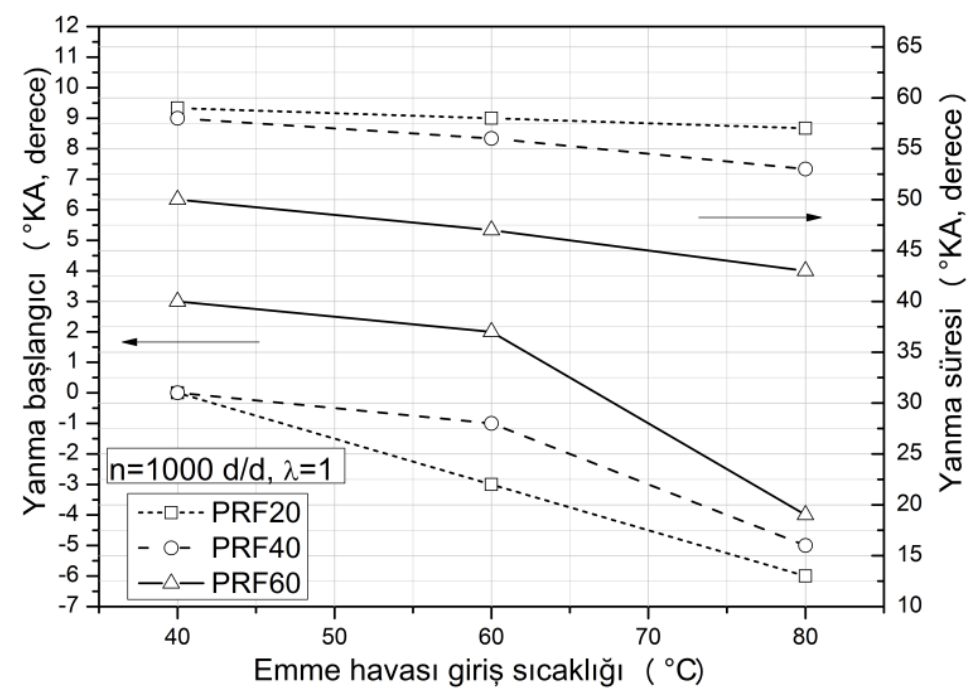

Şekil 5. Yanma başlangıcı ve yanma sürelerinin değişimi (The variation of start of combustion and combustion duration)

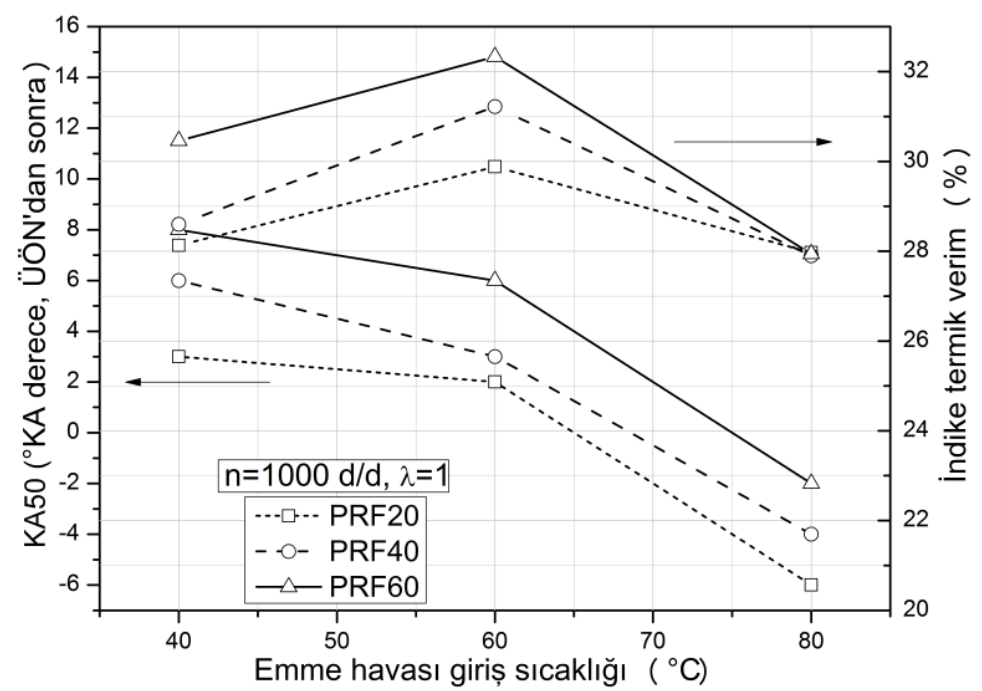

Şekil 6. RCCI yanmasında KA50 ve indike termik verimin değişimi (The variation of CA50 and indicated thermal efficiency in RCCI combustion)

RCCI yanmasında düşük 1Sı ve pompalama kayıpları verimin azalmasına engel olmaktadır. Daha fazla net iş ve azalan isı transfer kayıpları sonucu termik verim artmaktadır [38]. RCCI yanmasında yanma verimi yanma fazının avansa alınması ile iyileşmektedir. Çünkü oksidasyon reaksiyonları için gerekli zaman ve
${ }^{\circ} \mathrm{C}$ emme giriş sıcaklığında \%81.1 elde edilmiştir. PRF60 yakıtına göre PRF40 ve PRF20 ile yanma verimi sırasıyla $\% 6.1$ ve \%10.06 azalmıştır. Daha homojen ve yanmaya daha uygun karışım ile yanma veriminin arttığ görülmektedir. 


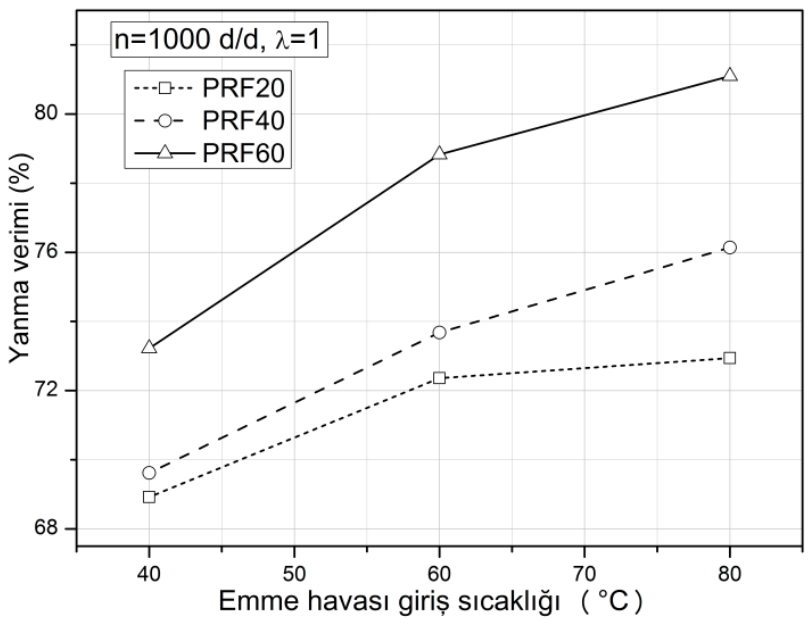

Şekil 7. Emme havası giriş sıcaklığına bağlı yanma veriminin değişimi (The variation of combustion efficiency depending on inlet air temperature)

Şekil 8'de RCCI yanmasında maksimum basınç artıŞ oranının değişimi görülmektedir. Emme havası giriş sıcaklığı arttıkça maksimum basınç artış oranı artmaktadır. Emme havası giriş sıcaklığı arttıkça 1sı dağılımı ve reaksiyon oranı hızlanmakta basınç artış oranı artmaktadır. Literatürde maksimum basınç artış oranı $10 \mathrm{bar} /{ }^{\circ} \mathrm{KA}$ tarafindan sinırlandırılmaktadır [27,28].Şekil 8 incelendiğinde bu sınırın hiçbir deneyde aşılmadığı görülmektedir. RCCI yanmasında düşük sicaklıkta meydana gelen oksidasyon reaksiyonları sonucu kararlı bir yanma gerçekleşmektedir. $1000 \mathrm{~d} / \mathrm{d}$ motor devri ve stokiyometrik oranda yapılan deneylerde ön karışım yakıt oranı arttıkça maksimum basınç artış oranının azaldığını ifade etmek mümkündür. Maksimum basınç artış oranı PRF40 ile $80^{\circ} \mathrm{C}$ emme giriş sıcaklığında $5.03 \mathrm{bar} /{ }^{\circ} \mathrm{KA}$ olduğu belirlenmiştir.

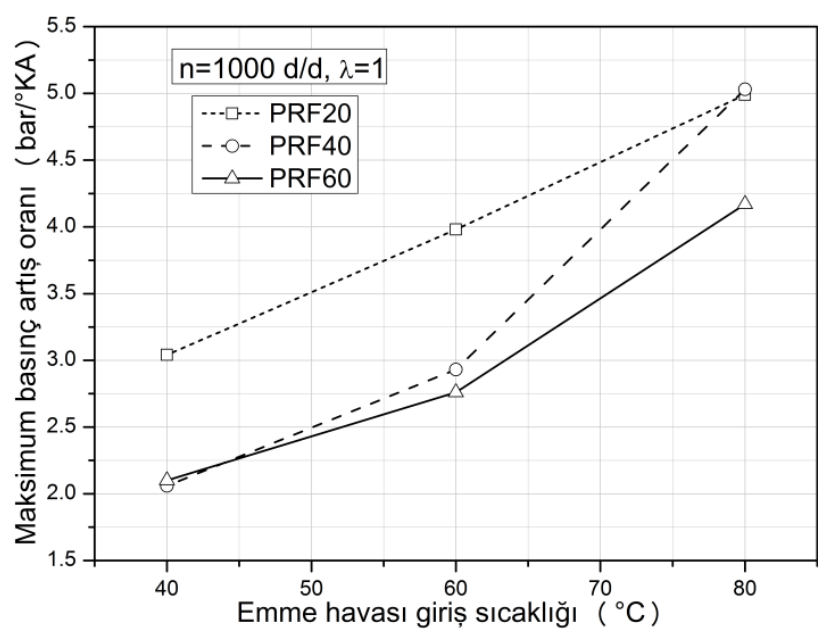

Şekil 8. Maksimum basınç artış oranının değişimimi (The variation of maximum pressure rise rate)

\section{CONCLUSIONS (SONUÇLAR)}

RCCI yanması yüksek termik verim ve düşük $\mathrm{NO}_{\mathrm{x}}$ ve is emisyonları ile araştırmacılar tarafından büyük ilgi görmektedir. Fakat özellikle düşük yüklerde azalan

yanma verimine bağlı olarak yanma ve motor performans karakteristikleri kötüleşmektedir. Bu çalışmada emme havası giriş sıcaklığının ve ön karışım yakıt oranının RCCI yanma ve motor performans karakteristikleri üzerindeki etkileri deneysel olarak araştırılmıştır. Emme havası sıcaklığı arttıkça maksimum silindir basınc1 ve 1s1 dağılımın arttığı görülmüştür. Aynı zamanda emme havası giriş sıcaklığ 1 ve ön karışım oranı arttıkça indike termik verim ve yanma veriminin arttığı görülmüştür. Maksimum indike termik verim PRF20 yakıtına göre PRF60 yakıtı ile \%7.4 artarak \%32.3 elde edilmiştir. Motor performansı açısından en uygun yakıtın PRF60 olduğu görülmüştür. Sonuç olarak RCCI yanmasının ön karışım yakıt oranı ve emme havası giriş sıcaklığından hassas bir şekilde etkilendiği, yanma fazının kontrol edilebileceği görülmüştür.

\section{SEMBOLLER (NOTATIONS) \\ $\boldsymbol{k}$}

$\boldsymbol{m}_{f}$ miktarı

$\mathbf{n}$ $d \mathrm{Q}$ $d \mathrm{Q}_{\text {heat }}$ $d \mathrm{Q}_{g r}$

\section{$Q_{L H V}$}

\section{$\boldsymbol{P}$}

V

$\theta$

$\lambda$

$\eta_{\text {yanma }}$

$t y_{\text {bas }}$

başlangıcı

ty $y_{\text {son }}$ sonu

\section{KISALTMALAR (ABBREVIATIONS)}

$\begin{array}{ll}\text { AC } & \text { Alternatif akım } \\ \text { BG } & \text { Beygir güç } \\ \text { BTDC } & \text { Üst ölü noktadan önce } \\ \text { CO } & \text { Karbon monoksit } \\ \text { HC } & \text { Hidrokarbon }\end{array}$




$\begin{array}{ll}\begin{array}{l}\text { HCCI } \\ \text { ateşlemeli } \\ \text { imep }\end{array} & \text { Homogen dolgulu sıkıştırma ile } \\ \text { KA } & \text { İndike ortalama efektif basınç } \\ \text { NO } & \text { Krank açısı } \\ \text { PCCI } & \text { Azot oksit } \\ \text { ateşlemeli } & \text { Ön karışım dolgulu sıkıştırma ile } \\ \text { PPC } & \text { Kısmi ön karışımlı yanma } \\ \text { PRF } & \text { Birincil referans yakıt } \\ \text { RCCI } & \text { Reaktif kontrollü sıkıştırma ile } \\ \text { ateşlemeli } & \\ \text { US EPA Birleşik devletler çevre koruma ajansı } \\ \text { ÜÖN } & \text { Üst ölü nokta }\end{array}$

\section{TEŞEKKÜR (ACKNOWLEDGEMENT)}

$\mathrm{Bu}$ çalışmanın yapılabilmesi için Hamit SOLMAZ 2219/A Doktora sonrası araştırma bursu kapsamında Tübitak tarafından desteklenmiştir. Ayrıca deney düzeneğinin kurulması için ''United States National Science Foundation (Grant No:1434273)', tarafindan finansal destek sağlanmıştır. Yazarlar Tübitak ve United States National Science Foundation'a teşekkür eder.

\section{KAYNAKLAR (REFERENCES)}

1. Ansari E., Poorghasemi K., Khoshbakht Irdmousa B., Shahbakhti M. and Naber J., "Efficiency and Emissions Mapping of a Light Duty Diesel - Natural Gas Engine Operating in Conventional Diesel and RCCI Modes," SAE Technical Paper, (2016).

2. Poorghasemi K., Saray R. K., Ansari E., Irdmousa B. K., Shahbakhti M. and Naber J. D., ''Effect of diesel injection strategies on natural gas/diesel RCCI combustion characteristics in a light duty diesel engine', Applied Energy, 199: 430-446, (2017).

3. Liu H.F., Xu J., Zheng ZQ, Li S.J. and Yao MF., 'Effects of fuel properties on combustion and emissions under both conventional and low temperature combustion mode fueling 2,5dimethylfuran/diesel blends', Energy, 62: 215-23, (2013).

4. Hanson R.M., Kokjohn S. L., Splitter D.A. and Reitz R.D., 'An experimental investigation of fuel reactivity controlled PCCI combustion in a heavyduty engine', SAE Int. J. Engines, 2010-01-0864, (2010).

5. Splitter D., Reitz R., Hanson R., 'High efficiency, low emissions RCCI combustion by use of a fuel additive", SAE International, 2010-01-2167, (2010).

6. Bessonette P.W., Schleyer C.H., Duffy K.P., Hardy W.L. and Liechty M.P., "Effects of fuel property changes on heavy- duty hcc1 combustion," $\boldsymbol{S A E}$ Technical Paper 2007-01-0191, (2007).

7. Kokjohn S., Hanson R., Splitter D., Kaddatz J. and Reitz R., 'Fuel reactivity controlled compression ignition (RCCI) combustion in light- and heavy-duty engines", SAE International, 2011-01-0357, (2011).
8. Theis J., Ura J., Li J., Surnilla G., Roth J.M. and Goralski C.T., "NOx release characteristics of lean no $_{x}$ traps during rich purges," SAE Technical Paper 2003-01-1159, (2003).

9. Ra Y. and Reitz R. D., 'A reduced chemical kinetic model for IC engine combustion simulations with primary reference fuels', Combustion and Flame, 155(4): 713-738, (2008).

10. Hardy W. and Reitz R., "A Study of the Effects of High EGR, High Equivalence Ratio, and Mixing Time on Emissions Levels in a Heavy-Duty Diesel Engine for PCCI Combustion," SAE Technical Paper, 2006-01-0026, (2006).

11. Kim J., Park S. W. and Reitz R. D., ' 'Improvements in the Performance and Pollutant Emissions for Stoichiometric Diesel Combustion Engines using a Two-Spray-Angle Nozzle", Journal of Automobile Engineering, 224(8): 1113-1122, (2010).

12. Opat R., Ra Y., Gonzalez D., M., Krieger R., Reitz R.D., Durrett R.P., Foster D.E., Siewert R.M., "Investigation of Mixing and Temperature Effects on $\mathrm{HC} / \mathrm{CO}$ Emissions for Highly Dilute Low Temperature Combustion in a Light Duty Diesel Engine," SAE Technical Paper, 2007-01-0193, (2007).

13. Kokjohn S. L., Reitz R. D. 'Investigation of the Roles of Flame Propagation, Turbulent Mixing, and Volumetric Heat Release in Conventional and Low Temperature Diesel Combustion", ASME J. Eng. Gas Turbines Power, 133: 10, (2011).

14. Hanson R., Kokjohn S., Splitter D. and Reitz R., 'Fuel Effects on Reactivity Controlled Compression Ignition (RCCI) Combustion at Low Load', $\boldsymbol{S A E}$ International, 2011-01-0361, (2011).

15. Dempsey A., Curran S., Storey J., Eibl M., Pihl J., Prikhodko V., Wagner R. and Parks J., 'Particulate Matter Characterization of Reactivity Controlled Compression Ignition (RCCI) on a Light Duty Engine', SAE International, 2014-01-1596, (2014).

16. Hanson R., Reitz R., 'Transient RCCI Operation in a Light-Duty Multi-Cylinder Engine”, $\quad \boldsymbol{S A E}$ International, 2013-24-0050, (2013).

17. Wissink M., Wang Z., Splitter D., Shahlari A. And Reitz R., 'Investigation of Pressure Oscillation Modes and Audible Noise in RCCI, HCCI, and CDC', SAE International, 2013-01-1652, (2013).

18. Pohlkamp K. and Reitz R., ''Reactivity Controlled Compression Ignition (RCCI) in a Single-Cylinder Air-Cooled HSDI Diesel Engine", $\quad \boldsymbol{S A E}$ International, 2012-32-0074, (2012).

19. Benajes J., Molina S., García A. and Belarte E., Vanvolsem M., "An investigation on RCCI combustion in a heavy duty diesel engine using incylinder blending of diesel and gasoline fuels", Applied Thermal Engineering, 63: 66-76, (2014).

20. Benajes J., Molina S., García A. And MonsalveSerrano J., "'Effects of direct injection timing and blending ratio on RCCI combustion with different low reactivity fuels", Energy Conversion and Management, 99: 193-209, (2015).

21. Zhu L., Qian Y., Wang X. and Lu X., 'Effects of direct injection timing and premixed ratio on 
combustion and emissions characteristics of RCCI (Reactivity Controlled Compression Ignition) with N-heptane/gasoline-like fuels", Energy, 93: 383392, (2015).

22. Li J., Yang W. M., Ana H. and Zhao D., ''Effects of fuel ratio and injection timing on gasoline/biodiesel fueled RCCI engine: A modeling study', Applied Energy, 155: 59-67, (2015).

23. Benajes J., Molina S., García A. and MonsalveSerrano J., 'Effects of low reactivity fuel characteristics and blending ratio on low load RCCI (reactivity controlled compression ignition) performance and emissions in a heavy-duty diesel engine", Energy, 90: 1261-1271, (2015).

24. Qian Y., Wang X., Zhu L. and Lu X., '’Experimental studies on combustion and emissions of RCCI (reactivity controlled compression ignition) with gasoline/n-heptane and ethanol/n-heptane as fuels", Energy, 88: 584-594, (2015).

25. Qian Y., Ouyang L., Wang X., Zhu L. and Lu X., "Experimental studies on combustion and emissions of RCCI fueled with n-heptane/alcohols fuels', $\boldsymbol{F} \boldsymbol{u e l}$, 162: 239-250, (2015).

26. Kakaee A-H., Rahnam, P. and Paykani A., 'Influence of fuel composition on combustion and emissions characteristics of natural gas/diesel RCCI engine", Journal of Natural Gas Science and Engineering, 25: 58-65, (2015).

27. Zhao H., ' $\mathrm{HCCI}$ and CAI engines for the automotive industry", Cambridge England: Woodhead Publishing Ltd., (2007).

28. Heywood J. B., "Internal combustion engine fundamentals", New York: McGraw- Hill; ISBN 007-028637-X, United States of America, (1988).

29. Stone R., 'Introduction to Internal Combustion Engines, Second Edition", Macmillan Press Ltd, ISBN 0-333-55083-8, Hong Kong, (1992).
30. Polat S., Kannan, K., Shahbakhti M., Uyumaz A. and Yücesu H.S., ' an experimental study for the effects of supercharging on performance and combustion of an early direct injection HCCI engine', Second International Reserch Conference on Engineering, Science and Management, Dubai, 51-57, (2015).

31. Anonymous 2,2,4-2-2-4Trimethylpentanecompound summary, PubChem Compound. USA: National Center for Biotechnology Information 26 March Identification and Related Records, 2005 (Retrieved March 2012).

32. Chang K., Lavoie G., Babajimopoulos A., Filipi Z. and Assanis D.N.,"Control of a Multi-Cylinder HCCI engine during transient operation by modulating residual gas fraction to compensate for wall temperature effects," SAE Technical Paper, 200701-0204, (2007).

33. Dempsey A. B., Walker N. R., Reitz R., ''Effect of cetane improves on gasoline, ethanol, and methanol reactivity and the implications for RCCI combustion', SAE International, 2013-01-1678, (2013).

34. Splitter D., Hanson R., Kokjohn S., Wissink M. and Reitz R., 'Injection effects in low load RCCI dualfuel combustion"', SAE International, 2011-240047, (2011).

35. Curran S., Hanson R. And Wagner R.,'’Effect of E85 on RCCI performance and emissions on a multicylinder light-duty diesel engine", $\boldsymbol{S A E}$ International, 2012-01-0376, (2012).

36. Splitter D., Wissink M., DelVescovo D. and Reitz R., "RCCI engine operation towards $60 \%$ thermal efficiency", SAE International, 2013-01-0279, (2013).

37. Curran S., Hanson R. and Wagner R., 'Efficiency and Emissions Mapping of RCCI in a light-duty diesel engine', SAE International, 2013-01-0289, (2013).

38. Hanson R., Curran S. and Wagner R., "Effects of Biofuel Blends on RCCI Combustion in a LightDuty, Multi-Cylinder Diesel Engine", $\quad \boldsymbol{S A E}$ International, 2013-01-1653, (2013). 